\title{
O ensaio como forma e a narrativa como método: encontros com a Teoria Crítica e o feminismo negro
}

\author{
Rafael Baioni do Nascimento ${ }^{1}$
}

\begin{abstract}
Resumo: Partindo do pensamento de autores da Teoria Crítica da Escola de Frankfurt, Theodor Adorno e Walter Benjamin, e de autoras do feminismo negro, em especial bell hooks e Patricia Hill Collins, este texto defende a escrita ensaística e narrativa como uma alternativa às formas enrijecidas de produção científica. Tanto o ensaio quanto a narrativa, por serem profundamente baseados na experiência, melhor refletem o objeto e suas transformações históricas, assim como as transformações subjetivas correspondentes. O enrijecimento da ciência manifesto no uso de fórmulas prontas de escrita dissertativa e na reprodução de metodologias consagradas pode ser identificado com o colonialismo (capitalista, racista, patriarcal). O pensamento desenvolvido pela Teoria Crítica e pelas autoras do feminismo negro podem atuar como diferentes caminhos de resistência a serem imitados e recombinados criativamente.
\end{abstract}

Palavras-chave: Ensaio. Narrativa. Experiência. Teoria Crítica. Feminismo negro.

\section{The essay as a form and the narrative as a method: encounters with Critical Theory and black feminism}

\begin{abstract}
Based on the thoughts of authors of the Frankfurt School Critical Theory, Theodor Adorno and Walter Benjamin, and of authors of black feminism, especially bell hooks and Patricia Hill Collins, this paper defends the essay and the narrative writing as an alternative to rigid forms of scientific production. Both the essay and the narrative, as they are deeply based on experience, better reflect the object and its historical transformations, as well as the corresponding subjective transformations. The hardening of science manifested in the use of ready-made essay writing formulas and in the reproduction of established methodologies can be identified with colonialism (capitalist, racist, patriarchal). The thinking developed by the Critical Theory and the authors of black feminism can act as different paths of resistance to be imitated and creatively recombined.
\end{abstract}

Keywords: Essay. Narrative. Experience. Critical Theory. Black feminism.

\section{El ensayo como forma y la narrativa como método: encuentros con la teoría crítica y el feminismo negro}

Resumen: Basado en el pensamiento de los autores de la Teoría Crítica de la Escuela de Frankfurt, Theodor Adorno y Walter Benjamin, y de las autoras del feminismo negro,

\footnotetext{
1 Doutor em Psicologia. Professor dos Programas de Pós-Graduação em Desenvolvimento Social e Educação da Universidade Estadual de Montes Claros. Minas Gerais. Brasil. E-mail: baionirafael@gmail.com. ORCID: https://orcid.org/0000-0003-0391-4169.
} 
especialmente bell hooks y Patricia Hill Collins, este texto defiende el ensayo y la escritura narrativa como una alternativa a las formas rígidas de producción científica. Tanto el ensayo como la narrativa, por estar profundamente basados en la experiencia, reflejan mejor el objeto y sus transformaciones históricas, así como las correspondientes transformaciones subjetivas. El endurecimiento de la ciencia manifestado en el uso de fórmulas de redacción de ensayos ya elaboradas y en la reproducción de metodologías establecidas puede identificarse con el colonialismo (capitalista, racista, patriarcal). El pensamiento desarrollado por la Teoría Crítica y las autoras del feminismo negro puede actuar como diferentes caminos de resistencia para ser imitados y recombinados creativamente.

Palabras clave: Ensayo. Narrativa. Experiencia. Teoría Crítica. Feminismo negro.

\section{Introdução}

Este texto surge da minha necessidade, enquanto professor universitário, de ajudar estudantes a superar o apego a uma maneira enrijecida e colonizada de se fazer ciências humanas bastante em voga nas universidades. A fórmula clássica - introdução, método, resultados e discussão - e os métodos consagrados até podem ser úteis para garantir um caminho minimamente seguro aos perdidos, mas também podem representar uma prisão para o pensamento.

Pensar de forma inteligente, aqui em uma definição provisória inspirada em Jean Piaget, é não apenas prever os problemas que vai enfrentar e escolher o método mais adequado em seu repertório, mas também modificar constantemente seus métodos e ampliar continuamente tal repertório, na tentativa - nunca plenamente bem-sucedida de abarcar a multiplicidade da experiência. O método enrijecido, correlato à razão enrijecida, é "burro" porque ele fixa aquilo que não pode ser fixado e com isso subverte seu objetivo: ao invés de servir para ver o mundo e aprender com ele, torna-se uma ferramenta mesquinha que tenta imprimir no mundo apenas a realidade limitada que ele mesmo permite enxergar.

Já perdi a conta de quantas vezes li trabalhos científicos inteiros com a sensação de que o método estava sendo fielmente seguido, enquanto o objeto de estudo não passava de um pretexto. É triste, porque se percebe um grande esforço sendo feito, porém que produz desconhecimento no lugar de conhecimento. De forma mais imediata, o desconhecimento do objeto de estudo em questão; mas, a longo prazo e de forma sistemática, o desconhecimento sobre o mundo e sobre si, seu lugar no mundo, sua história, sua posição nesse jogo de forças desigual e seu próprio potencial de resistência e transformação. 
É para nadar contra essa corrente que faço aqui algumas reflexões com base no pensamento de autores da primeira geração da Teoria Crítica da Escola de Frankfurt, principalmente Theodor Adorno e Walter Benjamin, e de autoras do feminismo negro, das quais me concentrarei principalmente em bell hooks, ${ }^{2}$ com apoio em Patricia Hill Collins, Lélia Gonzalez, Audre Lorde e Grada Kilomba. Se a razão enrijecida e colonizadora é muito parecida onde quer que se manifeste porque é justamente uma realização desse desejo de dominação de uns sobre todos os outros, a resistência a ela costuma produzir manifestações bastante diversas entre si - tal como é o pensamento de intelectuais de esquerda de origem judaica, como Adorno e Benjamin, e de feministas negras como hooks e Collins. Isso não quer dizer que não haja pontos de encontro ou relações possíveis de serem estabelecidas. Nós, os desfavorecidos de todas as sortes, temos muito a aprender uns com os outros.

Não é só essa fórmula introdução, método, resultados e discussão que deve ser posta em questão, mas toda fórmula. Thomas Kuhn, em seu clássico ensaio A estrutura das revoluções científicas, originalmente publicado em 1962, já defendia que mesmo nas ciências naturais há uma tendência de enrijecimento dos métodos, dos objetos escolhidos e dos problemas de pesquisa elegíveis por um determinado campo da ciência quando este se consolida, concomitante a um esquecimento - e proscrição - dos processos mais livres e intuitivos, presentes antes de sua consolidação. Para ele, a consolidação de um campo nunca é uma aproximação da verdade, mas o estabelecimento de um consenso em um determinado grupo. Esse consenso, chamado por ele de paradigma, é frequentemente substituído, na história da ciência, quando outras ideias que ameaçam ou desestabilizam o consenso surgem e ganham hegemonia (Kuhn, 1998). Nas ciências humanas e sociais, onde consenso e hegemonia são mais raros, o que vemos frequentemente são múltiplas tentativas de simular o mesmo enrijecimento teórico e metodológico de campos ditos consolidados das ciências naturais na esperança de partilhar seu prestígio.

Michel Foucault, no primeiro volume de sua História da sexualidade, originalmente publicado em 1976, vai mais longe e defende a tese de que esses consensos estruturantes de campos de saber são também estratégias de poder. A produção de conhecimento, longe de ser um trabalho de desvelamento do mundo como em sua versão positivista -, não é pensada por Foucault apenas como uma

\footnotetext{
${ }^{2}$ Pseudônimo grafado em minúsculas.
} 
interpretação ou uma disputa de interpretações da realidade, mas enquanto estratégias de controle e resistência. A sexualidade, por exemplo, não foi descoberta no século XIX, como pensam alguns, depois de a razão ter vencido o preconceito puritano, religioso e repressor; para Foucault, a ciência do século XIX, em especial a biologia e a medicina, criaram a sexualidade tal como a conhecemos, produzindo efeitos sociais de amplas dimensões, não possíveis anteriormente - como o controle populacional -, e também permitiu o surgimento de fenômenos de resistência antes inimagináveis - como movimentos identitários de minorias sexuais (FOUCAULT, 1988).

Essas ideias - ciência como consenso e como estratégias de poder - já estavam presentes nos autores da primeira geração da Escola de Frankfurt, que escreveram suas principais obras entre o final das décadas de 1930 e 1960. E podemos dizer que já estavam também presentes no feminismo negro - mais difícil de delimitar temporalmente. Ainda que boa parte das publicações de autoras autodeclaradas feministas negras datem da década de 1970 em diante, a característica distinguidora do pensamento dessas autoras é propor-se enquanto continuidade em relação ao pensamento de outras mulheres negras silenciadas no passado.

Essas duas tradições se posicionam radicalmente contra a postura científica que pretende instaurar um sujeito universal - $o$ sujeito do conhecimento - e definir como finalidade da ciência o domínio, por esse sujeito, de todo o restante do mundo natureza, coisas, outras pessoas. Essa postura científica é uma farsa, uma defesa velada dos interesses de homens brancos cristãos burgueses - grandes proprietários, grandes empresários, banqueiros - dos países centrais no capitalismo global - ou mesmo homens burgueses fora da Europa e dos EUA que partilham com os anteriores os desejos de conquista e os benefícios trazidos pela exploração de outros. Por vezes, podemos simplificar e dizer somente "o capitalismo", para designar toda a estrutura institucional, social e cultural que é maior que esses homens, mas não podemos esquecer que, no fim das contas, quem sustenta essa ciência enrijecida, quem decide para onde é direcionado o dinheiro nos investimentos em pesquisa, na construção e manutenção de universidades, institutos de pesquisa, museus, bibliotecas, escolas etc. são eles, os detentores do poder político e econômico no mundo atual. Se não podem ser responsabilizados em nível de consciência individual - pois mesmo suas consciências podem ter sido alijadas -, certamente devem ser responsabilizados enquanto grupo.

Para dar materialidade e mostrar como isso aparece mesmo em um simples 
trabalho apresentado em congresso científico, podemos destacar as incansáveis tentativas de dar sustentação a um sujeito universal do conhecimento através de uma linguagem fria e impessoal. Elas ocorrem quando o estilo da narrativa científica faz um esforço para parecer que aquele texto (trabalho, pesquisa etc.) poderia ter sido escrito por qualquer pessoa racional e teria percorrido o mesmo caminho, chegado aos mesmos resultados etc. Um texto que se esforça para parecer que poderia ter sido escrito por todos e por ninguém e que, portanto, reflete uma verdade imparcial e incontestável. Em geral, essas tentativas vêm acompanhadas de um segundo fator, cujo efeito também é deletério: a hierarquização das ideias. Trata-se da crença de que esse caminho percorrido pelo sujeito universal é o melhor dos caminhos, de que os conceitos, categorias, problemas e soluções que ele encontra são os mais racionais e os mais importantes segundo uma ordem estabelecida, e que todos os outros são parciais, superficiais, confusos, acessórios, imaturos, femininos ou primitivos.

Essa ciência de um caminho só é um correlato da estrada colonial que desde o século XVI atravessa os territórios do Sul sem respeitar o terreno e os caminhos antes trilhados, pilhando tudo o que considera de valor e destruindo o que lhe faz resistência. Nessa estrada todos têm que aprender a falar como o homem branco burguês europeu, ou não será escutado.

Mas há resistência, e meu objetivo aqui é mostrar como o ensaio para os frankfurtianos e a narrativa para as feministas negras são formas que os excluídos encontraram de transmitir sua experiência intelectual, e que se não queremos continuar emprestando nossos corpos para que o colonizador sustente sua ciência através de nós, precisamos parar de usar de seus métodos, de imitar sua linguagem, e nos dedicar a aprender com aqueles que há séculos tentam trilhar outros caminhos e transmitir o que aprenderam.

\section{O ensaio pela perspectiva de Theodor Adorno}

“O ensaio como forma", publicado originalmente em 1958, na coletânea Notas de literatura I, é um texto central para quem procura fundamentos para suas suspeitas contra a forma enrijecida da ciência atual. Nele, Theodor Adorno opõe o ensaio à dissertação. Mas a dissertação tem que ser entendida aqui como um texto que se pretende objetivo (livre da subjetividade), com definições conceituais precisas a priori, 
com procedimentos sistemáticos e resultados generalizáveis. O ensaio, por outro lado, sabe que a objetividade precisa da subjetividade e que não adianta se apoiar em definições precisas a priori, porque os conceitos são históricos e em constante transformação; reconhece que os procedimentos sistemáticos geralmente não dão conta de abarcar a realidade - mais complexa que a simplificação sistemática - e também que nem todos os resultados são generalizáveis, que o universal atemporal é uma ideia que precisa estar o tempo todo em tensão com o particular histórico, se não é ideologia.

No contexto de Adorno, a academia também estava presa em métodos rígidos. Ele diz, por exemplo, que "a atualidade do ensaio é o anacrônico" e que "a hora lhe é mais desfavorável do que nunca" (ADORNO, 2003, p. 44), justamente porque o contexto em que se encontrava era avesso a tudo que o ensaio representava:

Ele se vê esmagado entre uma ciência organizada, no qual todos se arrogam o direito de controlar a tudo e a todos, e onde o que não é talhado segundo o padrão do consenso é excluído ao ser elogiado hipocritamente como "intuitivo" ou "estimulante"; e, por outro lado, uma filosofia que se acomoda ao resto vazio e abstrato, ainda não completamente tomado pelo empreendimento científico, e que justamente por isso é visto pela ciência como objeto de uma ocupação de segunda ordem. (ADORNO, 2003, p. 44)

Adorno rejeita a ciência do consenso, que exclui o que não segue seus padrões, rejeita a filosofia abstrata, descolada da experiência e que gira em torno de si mesma, e, por fim, rejeita ainda a separação rígida entre ciência e filosofia, muito comum entre nós também, segundo a qual tudo que não cabe no método científico positivista recebe o rótulo de "filosófico" e é tirado do jogo, como na minha infância uma criança pequena era excluída pelas mais velhas da brincadeira com o rótulo de "café com leite". Para Adorno, a separação entre filosofia e ciência aconteceu historicamente, nas instituições, nos livros etc., mas não se sustenta sob um exame mais detido, tanto do ponto de vista de suas origens quanto do funcionamento atual de toda ciência e de toda filosofia válidas, pois a ciência não pode abrir mão dos conceitos (terreno a princípio da filosofia) nem a filosofia pode abrir mão da empiria e da experiência (terreno a princípio da ciência).

A opção de Adorno pelo ensaio é também uma crítica à separação rígida entre razão (filosofia e ciência) e arte. Em nenhum momento ele diz que o ensaio será um meio para transformar a filosofia e a ciência em arte. E sim que o ensaio resgata 
procedimentos expressivos proscritos na filosofia e na ciência e que ainda são encontrados na arte. Essa intenção já está no título. Dizer que o ensaio é uma "forma" é um posicionamento teórico e político, quando a razão se apresenta de forma cristalizada e ao mesmo tempo alega ser independente das formas, em favor de supostos conteúdos puros. É um modo de mostrar como a ciência e a filosofia também possuem formas e atribuem formas, também são expressão. Adorno não quer igualar ciência e filosofia à arte, mas mostrar como há razão construtiva na arte assim como há razão expressiva na ciência e na filosofia.

Sobre essa separação histórica entre filosofia e ciência de um lado e arte de outro, que não pode ser desfeita em um passe de mágica (ADORNO, 2003, p. 20), podemos pensar também com base em outro trabalho de Adorno, em conjunto com Max Horkheimer, Dialética do esclarecimento (1985), originalmente publicado em 1944. Nessa obra fica claro como para os autores essa separação está ligada historicamente à separação entre a razão e o mito. O que já havia de explicação racional na narrativa mítica tenta, com o estabelecimento da filosofia e da ciência, se tornar independente do caráter circular e conservador do mito (ao menos do mito cristalizado), assim como a preocupação com a forma nos rituais mágicos tenta se tornar independente de fins práticos diretos por meio do estabelecimento de um domínio independente para a arte.

Para eles, essa separação filosofia-ciência-arte foi uma tentativa válida de superar problemas da explicação mítica e limitações de liberdade formais dos rituais mágicos. Acontece que a razão ocidental, nessa busca de independência e liberdade, acabou recaindo em outra prisão, que é, por exemplo, a circularidade do método rígido para a ciência e o menosprezo pela filosofia e pela arte. Um método rígido, a fetichização da técnica, o apagamento do sujeito e outros procedimentos correlatos acabam funcionando como uma segunda natureza, isto é, como forças superiores e inalteráveis que subjugam o pensamento, leis das quais não temos controle e que nos ameaçam e subordinam o tempo todo - exatamente como ocorria com a explicação mítica.

A forma ensaio vai ser utilizada por muitos autores, e defendida explicitamente por Adorno, como uma estratégia de honrar esse impulso do pensamento ocidental de se separar da repetição do mito sem cair na repetição da ciência, de honrar o desejo de liberdade sem sacrificar toda a liberdade - como fazem a ciência e a filosofia enrijecidas. Em outros trabalhos de Adorno, como em Teoria estética (2006), ele mostra 
como a razão ocidental tem na arte uma forma de manifestação que em muitos momentos foi superior à ciência e à filosofia - ao não rejeitar a razão mimética, por exemplo - e que muito pode ser aprendido pela filosofia e pela ciência com a arte. Mas esse não é objetivo em "O ensaio como forma". Neste, o acento está em como já existe uma tradição no pensamento ocidental que se opõe à ciência e à filosofia enrijecidas, que se assemelha com a arte em alguns aspectos e que, ao mesmo tempo, não se confunde com a arte.

Onde se assemelham, para dizer de maneira resumida, é na importância da forma para o conteúdo - ou na não separação entre forma e conteúdo. O modo de exposição é tão importante quanto o exposto porque faz parte do exposto. E esse modo, longe de ser arbitrário, reflete a experiência do autor. Por outro lado, o ensaio não se confunde com a arte por trabalhar com conceitos a fim de explicar fenômenos, ou ao menos de estabelecer relações conceituais entre objetos, fatores não necessários na arte.

Adorno não diz que a forma ensaio é um salvo-conduto, que basta usá-la e está tudo resolvido. Ela também pode capitular e se tornar conformismo, como ele diz, quando o ensaio está mais preocupado em agradar ao público e submetido, portanto, a interesses do capital, não à lógica inerente da matéria do ensaio. A forma ensaio, tal como a tradição de Montaigne, Benjamin etc., tem suas próprias exigências internas, as quais, de forma aparentemente paradoxal, também são exigências externas. O ensaio se propõe a ser um trabalho da experiência intelectual do autor (interna, subjetiva) e ao mesmo tempo ser fiel aos objetos e à relação do sujeito com esses objetos (externa, objetiva), pois abrir mão da subjetividade seria renunciar um importante elemento da objetividade, já que a subjetividade é um objeto também, entre outros. ${ }^{3}$

Pode parecer confuso dizer que o sujeito é um objeto entre outros, mas é mais simples do que parece. Piaget (1999) explica isso muito bem quando fala que o bebê enxerga o mundo sob apenas um ponto de vista, que é o seu, com o mundo girando ao seu redor, um mundo fragmentado e despersonalizado, de eventos, repetições, ações e efeitos interessantes. Nem existe um "eu" ainda nesse momento, porque o "eu” só vai poder existir quando houver o reconhecimento de que os outros existem e que formam unidades coerentes e contínuas, aí então esse eu mais velho pode também se reconhecer

\footnotetext{
3 Nisso o pensamento de Adorno e Donna Haraway (1995) coincidem. Nesse importante trabalho, bastante citado inclusive entre as feministas negras, Haraway mostra como a subjetividade, rotulada de "feminina", foi expulsa da ciência, e que resgatarmos a dignidade da subjetividade é um meio de nos aproximarmos da objetividade possível.
} 
como uma unidade, igual aos outros, mas ao mesmo tempo diferente deles, por ocupar sua posição única no todo. Da mesma forma é a subjetividade na razão não enrijecida, ela é humilde e empática, ao reconhecer-se como um objeto entre outros. Quem se torna um buraco negro que arrasta tudo para si, sem plena consciência de sua própria existência, é a subjetividade negada e expulsa pela ciência, e que continua lá, "dando as cartas" - como um "retorno do recalcado", para usar uma metáfora psicanalítica.

Só uma ressalva: talvez haja mais razão no mito do que Adorno e Horkheimer puderam admitir. Eles dizem que a razão recaiu no mito e que o mito já era esclarecimento - essa é a dialética do esclarecimento -, porém não se dedicaram tanto à análise do mito quanto analisaram a razão, o que pode dar margem a interpretações perigosas. Isso porque "mito" é um nome genérico para uma imensidade de fenômenos variados e em constante transformação. Pode ser, por exemplo, que em outras culturas não ocidentais tenha existido, ainda exista ou venha a existir formas míticas de racionalidade não enrijecidas, de forma semelhante ao que acontece com a filosofia, a ciência e a arte. Essa separação histórica entre ciência, filosofia, arte e mito é um evento da história do Ocidente, e não de toda a humanidade. Sem mencionar também que, mesmo na história do Ocidente, razão e mito convivem de perto na religiosidade, em suas várias e mutáveis formas, as quais também podem ter seus méritos em uma interpretação racional (não enrijecida) do mundo. Faço essa ressalva para não aceitarmos muito rapidamente a ideia iluminista, que às vezes aparece nos frankfurtianos, de que há uma superação do mito e da religião pela filosofia e pela ciência. Talvez este seja um resquício etnocêntrico e imperialista, uma dívida que podemos pagar por eles, antes de invalidar todo seu pensamento com um gesto de repúdio.

Esse é um dos motivos pelos quais é tão importante para mim relacionar a forma ensaio aqui com a narrativa biográfica nas autoras do feminismo negro. Nem todos os grupos seguiram os mesmos caminhos de resistência à razão enrijecida que a camada dos intelectuais europeus burgueses em seu processo de autocrítica, e não podemos achar que toda crítica se resume à reprodução da autocrítica desses últimos.

Adorno, no texto citado, contrasta a forma ensaio com as regras do método de Descartes, um dos fundamentos da razão ocidental moderna. Enquanto para Descartes, em Discurso sobre o método, de 1637, o pensamento deve partir de 1) ideais claras e distintas; 2) dividir os fenômenos em partes elementares; 3 ) ir sempre do mais simples 
para o mais complexo; e 4) abarcar tudo. No ensaio os conceitos 1) são de difícil apreensão, em sua história e campo de forças; 2) não podem ser vistos apenas como elementos separados, pois estão sempre em relação; 3) não possuem uma ordem de importância; e 4) não pretendem abarcar tudo. Tentarei abordar agora, de forma esquemática e didática, os aspectos apontados por Adorno e algumas possíveis aplicações para a nossa escrita acadêmica, todos profundamente interrelacionados:

a) $\mathrm{O}$ ensaio recusa definições. Em vez disso, prefere que os conceitos se tornem mais claros no decorrer da escrita e "mais precisos pelas relações que engendram entre si”. (ADORNO, 2003, p. 28). Adorno critica muito essa falsa impressão de precisão que a ciência enrijecida tenta passar com suas definições. Quase todo trabalho positivista começa com uma apresentação de definições. Elas são estáticas, fechadas e não dão conta de abarcar os objetos, que são sempre maiores, mais complexos do que aquilo que cabe em uma definição. Adorno diz que esse pensamento que tenta igualar as ideias às coisas tem uma "compulsão à identidade" e defende um pensamento "negativo", não identitário. ${ }^{4}$ Os conceitos, melhores que as definições, são históricos e difíceis de apreender. É trabalhoso, e é bom que seja assim. Evitemos as definições - a não ser que sejam introdutórias e provisórias - e procuremos em cada trabalho mostrar como os conceitos são ferramentas do pensamento que estão em constante transformação. Se vamos falar de gênero, por exemplo, temos que pensar um conceito de gênero desenvolvido historicamente - quando, em que contexto, por quem, quais efeitos produziu e com quais outros conceitos se relaciona. Não basta um ou dois parágrafos dizendo "gênero é tal coisa". O que é "gênero" é uma grande disputa, não só teórica, mas na realidade da vida cotidiana.

b) O ensaio é assistemático. "Não almeja uma construção fechada, dedutiva ou indutiva” (ADORNO, 2003, p. 25). Não tenta abarcar toda uma realidade de forma definitiva. Isto é, não começa do princípio de tudo e não pretende colocar um ponto final. Ele começa onde está o interesse de quem escreve, segue o caminho de sua relação com o objeto e termina quando a relação estabelecida é satisfatória. Leio muitos trabalhos que começam de "Adão e Eva", como diz Adorno, que tentam remontar aos primórdios da humanidade. Voltando ao exemplo anterior, ao estudar gênero não precisamos nos remeter às primeiras aparições desse fenômeno na Pré-História, no Egito Antigo, na Grécia Antiga etc. Geralmente esses caminhos vão realizar

\footnotetext{
${ }^{4}$ Adorno reflete extensamente sobre isso em sua obra de maturidade, Dialética negativa (2009).
} 
simplificações grotescas, generalizações e saltos temporais inaceitáveis. Comecemos do problema onde ele nos afeta, da nossa experiência com ele, e escrevamos sobre como nos afeta ou afetou outras pessoas de forma semelhante. A menos que seu objetivo seja estudar o passado, claro. Mas ainda assim, sem grandes pretensões de generalização, sem querer extrair leis de funcionamento. Adorno diz que "o ensaio pensa em fragmentos, uma vez que a própria realidade é fragmentada" (ADORNO, 2003, p. 35). Não ser sistemático é uma fidelidade à realidade, não é erro nem capricho.

c) $\mathrm{O}$ ensaio não hierarquiza o conhecimento. Nesse sentido, Adorno diz que o ensaio "coordena os elementos, em vez de subordiná-los" (ADORNO, 2003, p. 43). A hierarquização é problemática porque pretende instaurar uma ordem definitiva num mundo que é esse jogo de forças constante. Adorno e Benjamin usam diversas vezes a ideia de "constelação" para indicar essa outra via, contrária à hierarquização - e que pode ser entendida até mesmo como um método. Os conceitos postos em constelação são todos igualmente importantes, em si e nas relações que estabelecem um com os outros formando um todo. Isso quer dizer, na prática, que não devemos escrever escolhendo conceitos que vão ser as chaves de leitura para determinado fenômeno e tentar tudo fazer encaixar nesses conceitos. Para continuar no exemplo, é difícil falar de gênero atualmente sem falar de sexo, sexualidade, raça, classe social e muitas outras coisas. Nenhuma categoria é mais importante que outra. Isso não quer dizer que no nosso trabalho específico um conceito não seja mais aprofundado e por isso, de um ponto de vista quantitativo, seja mais importante, ocupe mais espaço, tenha mais atenção etc. Porém, o tempo todo a nossa escrita tem que apontar para sua limitação e para o que está para além dela como igualmente importante.

d) O ensaio "renuncia ao ideal da certeza" (ADORNO, 2003, p. 30), se apresentando não em termos de certo e errado, mas como uma "configuração" que aponta para um "campo de forças" (ADORNO, 2003, p. 31). Sua base é a "experiência humana individual", e não "a verificação de teses já comprovadas por sucessivos testes" (ADORNO, 2003, p. 23). Os conceitos escolhidos, os objetos abordados e as relações estabelecidas seguem o caminho da experiência, do aprendizado individual, e não de manuais ou de outros conjuntos de regras estabelecidas de antemão. Isto é, se os conceitos são históricos e têm uma relação também histórica com os objetos, o ensaio vai representar uma determinada posição do sujeito que o escreve dentro de um jogo de forças bastante complexo. Devemos ter ao escrever, portanto, menos a postura de quem 
diz qual é "a verdade", o que é "o certo", e mais apresentar o nosso ponto de vista. Ao mesmo tempo é importante que este não seja tomado como "mero ponto de vista", no sentido de uma simples opinião. Ele é um ponto de vista construído nesse processo rigoroso de trabalho do sujeito com os conceitos e os objetos. Não é um capricho do pensamento particular, mas um testemunho do pensamento localizado.

Claro que existem ideias erradas, não só por serem imprecisas ou enganosas, quanto por serem prejudiciais. Rejeitar o ideal de certeza e evitar hierarquizar não é se entregar ao relativismo. Renunciar à pretensão de Verdade, com $v$ maiúsculo universal, atemporal etc. - não implica renunciar a um teor de verdade - histórico, relacional etc. Esse teor de verdade aparece no decorrer do trabalho e entre trabalhos, é um produto da experiência, da reflexão e da crítica.

\section{Narrativa e feminismo negro}

Eu comecei a estudar os feminismos depois de me mudar para Montes Claros, no norte de Minas Gerais, quando passei em um concurso para professor da Universidade Estadual de Montes Claros. Antes disso, eu vivia na capital de São Paulo, onde fiz mestrado e doutorado estudando Teoria Crítica. Na graduação eu militava em um grupo LGBT ligado ao DCE-USP e fazia parte de um laboratório de estudos sobre preconceito, porém, os feminismos ainda me pareciam algo distante. Rememorando, me parece muito estranho ter passado doze anos como estudante na Universidade de São Paulo, uma das maiores universidade do país, e não ter sido confrontado com escritos feministas. Talvez eu tenha perdido oportunidades em disciplinas optativas ou cursos livres. De qualquer forma, isso é um indício sobre como os feminismos estavam distantes do currículo, mesmo em um curso como o de Psicologia.

Em Montes Claros, foi minha experiência enquanto uma pessoa LGBTQIA+ em um contexto extremamente conservador que me despertou para essa área de estudos. Uma experiência que foi coletiva também, pois foi através do meu encontro enquanto docente com estudantes LGBTQIA+ que passamos a nos reunir para rodas de discussão e, mais tarde, fundar o (In)Serto, um projeto de extensão sobre diversidade sexual e de gênero que transformou a cara da universidade e nos transformou. Eu continuei estudando Teoria Crítica, que ainda constitui um dos pilares das minhas reflexões e atuação, ao mesmo tempo que percebi haver um sem-número de questões, no caso sobre 
o que eu e as pessoas a minha volta estavam vivendo, que a Teoria Crítica não poderia dar conta.

Já estudando feminismos, foi um percurso chegar até os escritos das feministas negras, pois as autoras mais citadas e debatidas eram todas brancas. Só nos últimos anos aumentaram as traduções de textos de feministas negras para o português, como os livros de Angela Davis e bell hooks, ou mesmo se têm dado mais atenção às nossas intelectuais negras, como Nilma Lino Gomes e Djamila Ribeiro, e "redescoberto" outras, como Lélia Gonzalez. Para mim foi uma grande lufada de ar fresco entrar em contato com esses escritos. Foi a primeira vez que li pessoas mais parecidas comigo que apesar de não me sentir confortável em me afirmar como negro em muitos contextos, por não viver boa parte das opressões a que estão sujeitas as pessoas negras, certamente me enquadro no que hoje em dia têm se convencionado chamar de PoC (person of color), expressão que no Brasil ainda soa pejorativa, mas que mundialmente tem ganhado papel de reivindicação política. Foi a primeira vez em muito tempo que ao ler não senti estar fingindo fazer parte de um grupo de intelectuais burgueses, dos quais eu, de avós analfabetos e pais operários, obviamente não fazia parte. Fazia tempo também, com exceção de alguns escritos de Antonio Candido e Paulo Freire, que não lia ideias extremamente complexas e relevantes numa linguagem clara, realmente escrita para comunicar. Foi a elaboração desses sentimentos que me fizeram prestar cada vez mais atenção ao papel da narrativa nos escritos das feministas negras.

Um livro bastante marcante para mim foi Ensinando a transgredir, de bell hooks, originalmente publicado em 1994, e que hoje é bibliografia básica de boa parte dos meus cursos - ao lado de "Educação após Auschwitz", de Adorno, o que mostra como o texto que aqui escrevo também é fruto das minhas reflexões durante a docência e do meu diálogo com colegas e estudantes. Nesse livro, hooks nos conta suas experiências educacionais, desde a escola segregada na infância no sul dos EUA até a experiência de professora universitária na Califórnia. É delicioso e muito instrutivo ler, por exemplo, sobre como a experiência da escola segregada na infância para ela foi mais libertadora do que a escola integrada na adolescência, sobre como ela foi marcada pelo pensamento de Paulo Freire (mas não deixou de dizer para ele, quando o encontrou pessoalmente, que achava sexista alguns aspectos dos seus escritos), sobre sua experiência enquanto estudante universitária e, depois, enquanto professora e pesquisadora. Ela conta como nas escolas segregadas as professoras - todas mulheres 
negras - conheciam cada estudante e o ensino focava o desenvolvimento não apenas cognitivo, mas também político, de consciência e valorização das pessoas negras, enquanto nas escolas integradas ela sentia que tinha que provar o tempo todo que podia ser tão boa quanto as pessoas brancas, sem lhe serem dadas as mesmas oportunidades. Ela conta sobre como foi importante para elas os cursos que fez sobre Estudos da Mulher na universidade, para voltar a perceber o aprendizado como algo relevante para a vida, sobre como infelizmente, algumas professoras universitárias brancas e intelectuais brancas silenciam intelectuais negras e sobre a experiência de ser uma professora que procurar ensinar com entusiasmo em um sistema educacional "bancário", nos termos de Paulo Freire - isto é, conteudista e despolitizador. A mensagem do título perpassa todo o livro: ensinar, em um contexto de desigualdades, injustiças e violências, não é só transmitir a cultura, é ensinar a romper com uma determinada cultura, é dar instrumentos para uma transformação coletiva.

Desse livro em diante, em todos os meus encontros com escritos de feministas negras - e também de feministas do sul e decoloniais -, saltava aos meus olhos essa marca da narrativa, autobiográfica, biográfica e ficcional. Uma autobiografia de Angela Davis, por exemplo, originalmente publicada em 1974, é frequentemente citado por outras escritoras como grande fonte de inspiração. Os escritos de Audre Lorde, poéticos e teóricos, são profundamente narrativos. Uma estudante excepcional, Larissa Ramos, me apresentou recentemente textos bastante atuais de Djamila Ribeiro e de Chimamanda Adichie - esta, inclusive, romancista - que vão nessa direção também. ${ }^{5}$ Destacarei a seguir apenas alguns dos muitos textos em que a narrativa é elemento central.

"Racismo e sexismo na cultura brasileira", de Lélia Gonzalez, publicado em 1984, um texto fundamental entre nós, mescla agudez teórica conceitual com vários estilos de narrativa. Ao lado de observações teóricas de grande complexidade, analisando o racismo por uma chave psicanalítica lacaniana, traz trechos como esse:

Não faz muito tempo que a gente estava conversando com outras mulheres, num papo sobre a situação da mulher no Brasil. Foi aí que uma delas contou uma história muito reveladora, que complementa o

\footnotetext{
${ }^{5}$ Aliás, aproveito para agradecer às mulheres que me apresentaram muitos dos textos que trabalho aqui, que muito me ensinaram e que são também companheiras de aprendizado, como a professora Ivete Almeida, da Universidade Federal de Uberlândia, e as professoras Cláudia Maia, Bárbara Figueiredo, Mônica Amorim e Daliana Antônio, mais diversas outras mulheres que compõem com a gente o Grupo de Estudos e Pesquisa Gênero e Violência da Unimontes.
} 
que a gente já sabe sobre a vida sexual da rapaziada branca até não faz muito: iniciação e prática com as crioulas. É aí que entra a história que foi contada prá gente (brigada, Ione). Quando chegava na hora do casamento com a pura, frágil e inocente virgem branca, na hora da tal noite de núpcias, a rapaziada simplesmente brochava. Já imaginaram o vexame? E onde é que estava o remédio providencial que permitia a consumação das bodas? Bastava o nubente cheirar uma roupa de crioula que tivesse sido usada, para "logo apresentar os documentos". E a gente ficou pensando nessa prática, tão comum nos intramuros da casa grande, da utilização desse santo remédio chamado catinga de crioula (depois deslocado para o cheiro de corpo ou simplesmente cc). E fica fácil entender quando xingam a gente de negra suja, né? (GONZALEZ, 1984, p. 234)

Muito ilustrativo, não somente por mostrar como um episódio narrado consegue transmitir uma nuance bastante complexa do racismo, mas também pela forma como começa, "não faz muito tempo a gente estava conversando com outras mulheres", e o agradecimento propositalmente coloquial "brigada, Ione", que ilustram outra característica dos escritos de feministas negras que é a referência constante a outras mulheres e a uma autoria coletiva. Bem diferente da disputa fálica masculina na história da razão ocidental, onde pode haver brigas homéricas para saber quem pensou primeiro ou quem foi o mais original, nos escritos das feministas negras vemos que a preocupação central está em partilhar o conhecimento, não em ser proprietária dele.

Um livro que tem ganhado grande destaque entre nós por sua recente tradução, Pensamento feminista negro, de Patricia Hill Collins (2019), originalmente publicado em 2000, é um exemplo interessante porque representa um esforço para fornecer uma visão panorâmica do feminismo negro estadunidense, e uma das coisas que mais chamaram a minha atenção durante sua leitura foi o cuidado de Collins em dar centralidade a relatos de intelectuais negras que atuaram muito antes da existência do feminismo negro propriamente dito. Vejamos por exemplo, o parágrafo de abertura do livro:

\footnotetext{
“Até quando as nobres filhas da África serão forçadas a deixar que seu talento e seu pensamento sejam soterrados por montanhas de panelas e chaleiras de ferro?", indagou Maria W. Stewart em 1831. Órfã desde os cinco anos de idade, entregue aos serviços da família de um clérigo como trabalhadora doméstica, Stewart lutou para se educar quando e onde pôde, de maneira fragmentada. Essa intelectual negra é uma pioneira: foi a primeira mulher negra a proferir discursos sobre questões políticas e legar cópias de seus textos, e ainda prenunciou uma miríade de questões que seriam retomas pelas feministas negras que a sucederam. (COLLINS, 2019, p. 30)
} 
Começar com a história de uma intelectual negra pioneira dá o tom do livro, de resgate e continuidade. E, tanto importante quanto, faz isso sem postular um suposto feminismo negro unitário. Trata-se antes de um reunir de histórias, tanto de pensadoras negras do passado quanto atuais, que trilham caminhos diversos, entre os quais Collins encontra afinidades, sem tentar reduzir todos a um denominador comum. Para a autora, o desenvolvimento do feminismo negro atual além de recuperar trabalhos que foram preservados, como o de Maria Stewart, deve também recuperar trabalhos que foram silenciados, como das feministas negras lésbicas, e o pensamento de mulheres "que não são comumente vistas como intelectuais" (COLLINS, 2019, p. 51). Ela diz:

Conforme a definição proposta nesta obra, as intelectuais negras não necessariamente são acadêmicas nem encontradas apenas na classe média negra. De fato, todas as estadunidenses negras que de alguma forma contribuem para o pensamento feminista negro como teoria social crítica são consideradas "intelectuais". (COLLINS, 2019, p. 51)

Ela dá o exemplo de Sojourner Truth, ativista feminista negra do século XIX, geralmente não considerada uma intelectual, que durante a vida não sabia ler nem escrever, mas que proferiu discursos que se tornam famosos e foram registrados por outras pessoas. Em um dos seus discursos mais famosos, proferido em uma convenção sobre os direitos das mulheres em 1851, ela teria dito:

Aquele homem ali diz que as mulheres precisam de ajuda para subir em carruagens, e ser carregadas quando há valas na passagem, e ter o melhor lugar onde quer que estejam. A mim, porém, ninguém nunca ajudou a subir em carruagem, a pular poças de lama, nem cede o melhor lugar! E por acaso não sou mulher? Olhem para mim! Olhem meu braço! Já arei, plantei trabalhei em estábulos, e homem nenhum se saía melhor do que eu! E por acaso não sou mulher? Eu era capaz de trabalhar e comer tanto quanto um homem - quando havia comida - além de aguentar chicotada! E por acaso não sou mulher? Pari treze filhos, e um por um foram vendidos como escravos. Quando chorei minha dor de mãe ninguém me ouviu, só Jesus! E por acaso não sou mulher? (TRUTH ${ }^{6}$ apud COLLINS, 2019, pp. 51-52)

Nesse trecho podemos notar o poder de reflexão e a crítica aguda à ideia de mulher enquanto universal. Uma das teses de base do feminismo negro, de que as mulheres negras têm uma luta que não se confunde com a das mulheres brancas ou com

\footnotetext{
${ }^{6}$ Esse registro do discurso de Sojourner Truth é citado por Collins a partir de LOEWENBERG, Bett J.; BOGIN, Ruth (Orgs.). Black women in nineteenth century American life. University Park; London: Pennsylvania State University Press, 1976, p. 235.
} 
a dos homens negros, está aí sintetizada de forma exemplar. Além disso, antecipa, por exemplo, críticas como a de Angela Davis (2016) em Mulheres, raça e classe, de 1981, segunda a qual a reivindicação feminista de acesso ao mundo do trabalho fora o doméstico é uma reivindicação das mulheres brancas de classe média e não de todas as mulheres, já que as mulheres negras sempre trabalharam, em condições precárias.

Essa é uma grande lição para nós, não apenas pessoas negras, mas também outras pessoas não brancas, brancas pobres e periféricas. Nossos antepassados e nós mesmos podemos ser desconsiderados enquanto intelectuais pela academia, mas isso não significa que não sejamos intelectuais, que não haja entre nós muito pensamento refinado e crítico, apenas codificado, por vezes, de uma forma não reconhecível imediatamente pela academia, como pela narrativa, pela arte, pelo mito, pela história de vida. E está mais do que na hora de a academia se abrir definitivamente para esse tipo de conhecimento.

Curioso apontar que essa frase repetida por Sojourner, "E por acaso não sou mulher?”, em inglês no original é “Ain't I a woman?", e que a contração “ain't” é uma marca da oralidade, especialmente entre as pessoas negras estadunidenses. É justamente essa frase que foi escolhida posteriormente para nomear esse discurso de Sojourner, não para apontar o erro em relação à norma culta, mas para subverter esse julgamento racista implícito na ideia de norma culta e exaltar a particularidade do uso da língua entre as pessoas negras nos EUA.

Curioso apontar também, que bell hooks escolheu essa frase como título de seu primeiro livro, Ain't I a woman: black women and feminism, de 1981, claramente como uma homenagem. Ela começa assim um dos capítulos do livro:

Mais de cem anos se passaram desde o dia em que Sojourner Truth se apresentou diante de um grupo de mulheres e homens brancos reunidos em um comício antiescravista em Indiana e descobriu os seios para provar que era de fato uma mulher. Para Sojourner, que percorreu o longo caminho da escravidão à liberdade, desnudar os seios era uma questão insignificante. Ela enfrentou seu público sem medo, sem vergonha, orgulhosa de ter nascido negra e mulher. No entanto, o homem branco que gritou com Sojourner: "Eu não acredito que você realmente seja uma mulher", inconscientemente expressou o desprezo e o desrespeito da América pela condição de mulher negra. Aos olhos do público do século 19, a mulher negra era uma criatura indigna do título de mulher; ela era um mero bem, uma coisa, um animal. Quando Sojourner Truth se apresentou diante da segunda convenção anual do movimento pelos direitos das mulheres em 
Akron, Ohio, em 1852, mulheres brancas que consideraram impróprio que uma mulher negra pudesse subir em um palanque público em sua presença gritaram: "Não a deixe falar! Não a deixe falar! Não a deixe falar!" Sojourner suportou seus protestos e se tornou uma das primeiras feministas a chamar a atenção delas para o destino das escravas negras que, compelidas pelas circunstâncias a trabalhar ao lado de homens negros, viviam a personificação do fato de que as mulheres podiam ser iguais aos homens no trabalho. (HOOKS, 1990, pp. 159-160, tradução nossa)

Note não apenas como a memória dessa feminista negra pioneira é resgatada também por hooks, mas como ela é resgatada. Pode-se perceber uma série de elementos narrativos, como o uso de diálogos e a suposição de sentimentos e estados de ânimo. Não há um compromisso com uma descrição precisa e fria da realidade - aspecto que veremos também mais adiante serem ressaltados por Walter Benjamin. O compromisso maior é com a transmissão da mensagem, que emociona, provoca empatia e, assim, é experienciada pelo ouvinte, que aprende e se transforma. Alguém poderia acusar hooks de estar inventando alguns desses detalhes - mentindo -, sem entender que hooks não precisava estar lá ou ser a própria Sojourner para saber como ela se sentiu, imaginar. E que isso é potência, não um erro ou mentira. Quem acredita que é possível uma descrição neutra e imparcial, é porque não enxerga que toda descrição que tem essa aparência serve a um propósito numa narrativa maior, colonial, contada há muito tempo pelos homens brancos burgueses cristãos e seus semelhantes.

Essa potência da narrativa, de unir as mulheres negras para além de suas vivências individuais, é bastante ressaltada por hooks. A começar pela escolha de usar o pseudônimo bell hooks - seu nome de batismo é Gloria Watkins -, em homenagem à sua tataravó, e a opção por usá-lo em letras minúsculas, uma escolha política, para chamar a atenção para a mensagem, e não para si mesma (BELL HOOKS, s. d.).

No ensaio "Revolucionary black woman", integrante do livro, Black looks: race and representation, de 1992, hooks sintetiza muito bem a importância da narrativa para o desenvolvimento de uma subjetividade feminista:

Pedagogia crítica, o compartilhar de informações e conhecimentos de mulheres negras com mulheres negras, é crucial para o desenvolvimento da subjetividade feminina negra radical (não porque as mulheres negras só podem aprender umas com as outras, mas porque as circunstâncias de racismo, sexismo e exploração de classe fazem com que outros grupos não busquem necessariamente promover nossa autodeterminação). (HOOKS, 1992, p. 56, tradução nossa) 
Inclusive sobre o uso da narrativa autobiográfica, ela complementa:

Quando as mulheres negras aprendem sobre minha vida, elas também aprendem sobre os erros que eu cometo, as contradições. Eles passam a conhecer minhas limitações e também meus pontos fortes. Eles não podem me desumanizar colocando-me em um pedestal. Compartilhando as contradições de nossas vidas, ajudamos uns aos outros a aprender como lidar com as contradições como parte do processo de nos tornarmos pensadores críticos, sujeitos radicais. (HOOKS, 1992, p. 56, tradução nossa)

Não podemos esquecer também a narrativa ficcional. Bell hooks faz questão de dar cursos sobre escritoras negras há muitos anos. Para ela, a narrativa ficcional está ligada à experiência e à utopia e é um importante lugar de disputa. Em Black looks isso fica bem claro, e pode-se encontrar diversas análises sobre romances escritos por mulheres negras. Não são simples histórias inventadas, são reflexões literárias baseadas nas vivências das mulheres negras. Essas histórias, hooks também não "coloca em um pedestal" - como nos aconselha a não fazer com sua própria história -, mas aponta contradições, aspectos mais e menos interessantes do ponto de vista de um desenvolvimento da autonomia e da liberdade das mulheres negras.

Para encerrar esta seção do texto, gostaria que fizéssemos um último exercício, a partir desse livro de hooks, Black looks, a respeito do modo com que, para as autoras do feminismo negro, a narrativa, especialmente em seu aspecto de comunhão, não deve estar fundamentada na idealização de uma irmandade natural ou essencial entre mulheres negras, mas um processo de elaboração do sofrimento, que aparece inclusive na forma de raiva umas para com as outras e de isolamento. Em Black looks, hooks nos conta como foi marcada por um ensaio de Audre Lorde chamado "Eye to eye: black women, hatred and anger”, presente na coletânea Sister outsider, de 1984. Nesse ensaio Lorde fala dos sentimentos negativos entre mulheres negras, algo que hooks vinha vivenciando ocasionalmente em recepções do seu trabalho. Ela cita Lorde:

[...] por que essa raiva se desencadeia de forma mais contundente contra outra mulher negra ao menor motivo? Por que eu a julgo de uma forma mais crítica do que qualquer outra, ficando furiosa quando ela não se mostra apta? E se por trás do objeto de meu ataque estivesse o rosto de mim mesma, que eu mesma não aceitei, o que poderia apagar o fogo alimentado por essas paixões recíprocas? (LORDE, 2007, p. 157, tradução nossa)

A princípio hooks critica a postura de Lorde nesse ensaio, por ser demais 
generalista e pressupor essa raiva entre mulheres negras enquanto um traço mais onipresente do que talvez fosse, principalmente porque ela mesma havia vivido outra experiência na infância em "igreja e escola segregadas", mais solidária entre mulheres negras. Mais ao final do texto, entretanto, ela reafirma a importância desse ensaio de Lorde e sua ênfase no encorajamento a mulheres negras serem mais afetuosas umas com as outras.

Lendo o ensaio de hooks e de Lorde, percebi como diferentes mulheres em diferentes momentos - lógicos, não necessariamente cronológicos - vivenciam também de forma diferente essa elaboração do sofrimento causado pelo racismo, pelo patriarcado e pelo colonialismo. Hooks, em sua infância, foi marcada por uma comunidade de mulheres que já havia caminhado bastante nesse processo de elaboração coletiva. Lorde, em seu texto, está testemunhando outro momento, das mulheres negras que ainda têm dificuldade de olhar nos olhos umas das outras. A construção dessa comunidade de apoio, das relações que dão margem a se pensar em um sujeito coletivo, é uma conquista: "Temos histórias de mulheres negras que curaram as feridas umas das outras, criaram os filhos umas das outras, lutaram nas batalhas umas das outras [...] Mas a conexão entre as mulheres negras não é automática [...]" (LORDE, 2007, pp. 164-165, tradução nossa).

Lorde sugere uma diferenciação entre dor (pain) e sofrimento (suffering). A dor é uma experiência que precisa ser reconhecida, nomeada e então transformada em outra coisa, em "força ou conhecimento ou ação" (LORDE, 2007, p. 188, tradução nossa). O sofrimento, por sua vez, seria o pesadelo de reviver uma dor não metabolizada, não reconhecida, repetitiva. Isto é, uma dor não elaborada.

Essa reflexão me chamou a atenção também porque esse é um tema central no livro de Grada Kilomba, Memórias da plantação, que li há pouco tempo. Publicado originalmente em inglês em 2008, recebeu uma tradução recente para o português e tem tido uma boa acolhida em nosso meio. Ele havia sido tema de alguns encontros do Grupo de Estudos e Pesquisa Gênero e Violência da Unimontes, do qual faço parte, mas não tinha me debruçado ainda com dedicação sobre ele. Chegando em Berlim - pois escrevo este texto em minha licença para pesquisa pós-doutoral na Freie Universität de Berlim -, fiquei impressionado ao ver o livro de Grada em lugar de destaque em muitas livrarias, então me voltei a ele. Ela é uma jovem autora portuguesa radicada em Berlim, onde fez o doutorado do qual o mencionado livro é um produto, e as experiências 
biográficas próprias e de outras mulheres negras (alemãs ou vivendo na Alemanha) que entrevistou em sua pesquisa ressoaram muito em mim. Ajudaram-me a elaborar algumas experiências desconfortáveis que vivi aqui ou me foram relatadas por pessoas não brancas próximas a mim. Grada parte de uma base teórica psicanalítica, sobretudo inspirada nos trabalhos de Frantz Fanon, mas também em uma leitura extensa das obras de bell hooks, frequentemente citadas, para apontar como há um trauma coletivo - da escravização, da colonização - que aparecem conectados a elementos psicológicos de um trauma individual. Uma de suas conclusões pode ser vista como uma atualização dessas reflexões feitas antes por hooks e Lorde sobre sofrimento e sua elaboração coletiva:

[...] o amor e a união emergem como uma tarefa política para reparar nossa historicidade individual e coletiva de perda e isolamento. Fomos, e ainda somos, privadas/os do nosso elo com a sociedade, fato que nos causa uma sensação interna de perda. Assim, a ideia de unidade é usada como um movimento político para superar a separação o segundo elemento do trauma. (KILOMBA, 2019, p. 222)

No trabalho de Grada Kilomba a narrativa também é um elemento central para essa elaboração do sofrimento e sua transformação em luta política. O que confirma a força dessa tradição e sua atualidade.

\section{O desaparecimento da narrativa para Walter Benjamin}

Quando falamos de narrativa e Teoria Crítica é difícil não pensar imediatamente no ensaio "O narrador: considerações sobre a obra de Nikolai Leskov", de Walter Benjamin, escrito em 1936. Nesse texto clássico, Benjamin dá continuidade e aprofunda a tese de Lukács, em Teoria do romance, de que o romance é a forma de prosa que corresponde à solidão do sujeito burguês, em contraposição aos aspectos mais coletivos da narrativa épica. Benjamin vai fazer outro caminho e falar principalmente da narrativa na cultura popular, da oralidade, e seu papel enquanto transmissão de experiência. ${ }^{7}$

Segundo Benjamin, um autor como Leskov, ainda que seja um escritor moderno que viveu no século XIX, não seria exatamente um romancista, como Dostoiévski, por utilizar a forma narrativa mais próxima à popular:

\footnotetext{
${ }^{7}$ Adorno parece concordar com Benjamin e reproduz as ideais centrais de "O narrador" em seu "Posição do narrador no romance contemporâneo", de 1954 (ADORNO, 2003b).
} 
O que distingue o romance de todas as outras formas de prosa contos de fadas, lendas e mesmo novelas - é que ele nem procede da tradição oral, nem a alimenta. Ele se distingue, especialmente, da narrativa. $\mathrm{O}$ narrador retira da experiência o que ele conta: sua própria experiência ou a relatada pelos outros. E incorpora as coisas narradas à experiência de seus ouvintes. O romancista segrega-se. A origem do romance é o indivíduo isolado [...] (BENJAMIN, 1987, p. 201)

Segundo ele, a narrativa dá conselhos, o que o romance já não consegue fazer, por seu foco no incomensurável da singularidade de um indivíduo. Ao final de um romance encontramos subjacente uma pergunta sobre "o sentido da vida", ao menos daquela vida singular, uma atitude até certo ponto niilista de contemplação da solidão, enquanto na narrativa encontramos uma "moral da história", não moralista, mas que tem sim fins práticos e até mesmo comunitários, ao querer ensinar algo (BENJAMIN, 1987, p. 2012). ${ }^{8}$

Além disso, a narrativa dá conselhos contando uma história, e não prescrevendo regras, como em uma abordagem moralista religiosa. E, por fim, a narrativa se contrapõe também à informação, que é pontual, impessoal e desconectada de uma história de longo prazo - que ele associa às notícias jornalísticas. A narrativa traz consigo todo um contexto vivido ou "ouvido dizer" de quem o viveu. A informação explica demais, quer ser transparente. A narrativa não, evita explicações, dá um exemplo, com múltiplas interpretações possíveis. A informação só tem valor enquanto é nova; a narrativa, por outro lado, preserva seu poder por muito tempo. E como a informação é impessoal, poderia ter sido trazida por qualquer um, a narrativa não, ela traz "a marca do narrador, como a mão do oleiro na argila do vaso" (BENJAMIN, 1987, p. 205).

No entanto, penso que precisamos enxergar o diagnóstico que Benjamin faz nesse trabalho: "a arte de narrar está em vias de extinção" (BENJAMIN, 1987, p. 197), com bastante cautela. Ele fala de um contexto burguês bastante específico, por exemplo, em que o romance e a imprensa - uma forma mais sofisticada, talvez, e outra mais degenerada -, se mostram mais adaptados à subjetividade do indivíduo urbano na sociedade capitalista ocidental do que a narrativa, associada à cultura popular.

\footnotetext{
${ }^{8}$ Os romances de formação, como os de Goethe sobre o personagem Wilhelm Meister, seriam uma tentativa de remediar esse isolamento individual com uma utopia coletiva. Nesse texto, Benjamin fala sobre isso com bastante ressalva, mas não desenvolve muito. Eu apostei bastante nessa via, de superação do isolamento burguês por meio dos projetos utópicos inerentes à arte romântica em outros trabalhos (NASCIMENTO 2014; 2021).
} 
Entretanto temos que enxergar esse diagnóstico como um diagnóstico de tendência, não uma descrição absoluta. Havia narradores ainda, nem que escassos, no entorno de Benjamin. E não seria ele próprio um narrador, especialmente se pensarmos em obras como "Infância em Berlin" e Passagens? Quando Benjamin diz, por exemplo, que "o grande narrador tem suas raízes no povo, principalmente nas camadas artesanais" (BENJAMIN, 1987, p. 214), podemos nos perguntar se em outros contextos menos burgueses e urbanos a narrativa ainda não seria mais presente e conservaria muito de seu poder.

O diagnóstico de Benjamin é, de toda forma, fundamental. Penso ainda que a frieza da escrita científica seria um terceiro grande exemplo - ao lado do romance e da imprensa - de enfraquecimento da narrativa - enfraquecimento, antes de tudo, da capacidade de ter experiências e de "intercambiar experiências" (BENJAMIN, 1987, p. 198). Entretanto, penso que devemos nos perguntar se estamos na mesma posição que Benjamin. Será que a narrativa para todos nós é realmente tão escassa que precisamos buscá-la em alguns poucos escritores que mantêm uma ligação com o "povo"? Não haveria outras fontes disponíveis de narrativa?

\section{Ciência, educação e experiência descolonizadoras}

Ao trazer aqui a narrativa no feminismo negro, acredito que podemos ver a potência viva e atuante da narrativa ainda hoje. Mesmo admitindo que a tendência massacrante ainda é a do abafamento da narrativa por essa força masculina, universalizante, patriarcal, racista, colonial etc., quanta potência nós temos, por outro lado, em nossas experiências subalternas, femininas, negras, de cor, LGBTQIA+, indígenas, do campo, periféricas etc. e que estão sendo transmitidas, às vezes com dificuldade, mas ainda assim transmitidas? Acredito que a intenção de Benjamin não era produzir um sentimento de derrota, ainda que ele possa ser lido dessa forma, mas disputar um lugar de maior prestígio para a narrativa e para a experiência entre os seus.

Nesse sentido, mesmo a nossa interpretação da tradição, e de autores como Adorno e Benjamin, é também a construção de uma narrativa - ou sua impossibilidade, caso interpretemos com a frieza acadêmica habitual. É difícil para mim não sentir que eles, Adorno e Benjamin, em muitos aspectos lembram mais a ciência do colonizador do que as feministas negras estadunidenses, por serem homens brancos europeus da 
classe burguesa - ainda que de origem judaica -, mas também pelas referências de leitura que pressupõem, pela dificuldade da linguagem, ${ }^{9}$ pelo contexto que evocam. Mas elas também podem ser interpretadas numa chave colonizadora, por serem estadunidenses, e pelo peso de dominação que a cultura estadunidense tem sobre nós. A questão central para mim, por isso, é como você experencia o seu encontro com esses autores e autoras ou outros que "falem ao seu coração". O que eles lhe transmitiram, o que lhe ensinaram, que conselhos lhe deram?

A minha experiência tem sido de muito aprendizado, teórico e prático, sobre como resistir a essa força massacrante do capitalismo racista, patriarcal e colonizador, e acho que não à toa autores como Adorno e hooks se dedicaram tanto ao tema da educação. Porque educação não é só o que fazemos na escola ou na universidade. Nos educamos brincando, lendo livros, vendo TV, conversando com amigos e, no caso aqui, também produzindo e consumindo ciência. Trata-se de saber se enquanto fazemos tudo isso estamos tendo uma experiência verdadeira ou estamos vivendo no automático, tentando nos adaptar ao papel que acreditamos que nos cabe numa ordem injusta e impossível de modificar.

Portanto, da próxima vez que for escrever um trabalho científico, pense se ele realmente precisa ter introdução, método, resultados e discussão ou se você está apenas reproduzindo de forma automática uma receita. Você tem familiaridade com o método escolhido e ele é realmente adequado ao seu objeto, ou é simplesmente o método que foi indicado ou mais utilizado na área? Os autores e autoras que utiliza, você compartilha com eles a mesma visão de mundo, faz as mesmas apostas, ou são só nomes para as definições instrumentais de que precisa? Eu costumo dizer que um texto de sua autoria é uma continuidade do seu corpo e que quem você cita são como tatuagens. Precisamos pensar bem nos símbolos que imprimimos em nossos corpos.

O ensaio pode ser uma opção a essa estrutura dissertativa tradicional, mesmo que seu trabalho envolva uma pesquisa empírica. O referencial teórico pode ser apresentado, o método pode ser descrito, os resultados apresentados e discutidos,

\footnotetext{
${ }^{9}$ Para mim o problema não é Adorno "escrever difícil", são seus seguidores imitando seu estilo. Nem todo mundo precisa escrever de forma fácil. Adorno, Jacques Lacan e Judith Butler escreveram obras que admiro e que não são fáceis de ler. Mas trazem em seus trabalhos muito conhecimento acumulado e reflexões bastante originais, sofisticadas e valiosas, que, precisaram a seu ver ser formuladas dessa forma. O uso que fazemos dessas obras, entretanto, é livre, ou ao menos deveria ser. Temos que ter em mente quem são nossos pares, quem é nosso "público", e usar uma linguagem que tenha como efeito o desenvolvimento uns dos outros, não o isolamento com aura de superioridade intelectual. Nada mais ridículo do que um colonizado falando sozinho e empolado com as palavras do colonizador.
} 
seguindo outra forma de escrita. De maneira semelhante, pergunte-se se seu texto não está sustentando indevidamente uma ideia de sujeito universal do conhecimento. Pergunte-se se você consegue se enxergar no seu texto. Por que você e não outra pessoa o escreveu? Seu texto também é sua voz. Você fala por si ou apenas empresta seu corpo para fazer ressoar a voz dos outros? A narrativa pode ser um recurso importante nesse momento, para se colocar no texto, inserir sua experiência e a experiência de outras pessoas como você.

Às vezes sentimo-nos na obrigação de nos conformar, por exemplo, quando uma revista ou evento científico pede um determinado formato enrijecido. Nesse caso, é preciso avaliar o quanto realmente precisamos nos sujeitar a isso - isto é, se não há outras opções válidas em outras revistas e eventos. Além disso, muitas vezes introjetamos as proscrições e não nos permitimos ter experiências intelectuais e de escrita mais autênticos mesmo quando não há um censor externo (tais como os pareceristas das revistas e os avaliadores de eventos).

Segundo minha experiência e segundo o que aprendi com esses autores e autoras trazidos aqui, sempre haverá algo de sofrido em escrever, porque o conhecimento autêntico é ao mesmo tempo uma elaboração do sofrimento vivido por nós e por nossos antepassados. Mas esse sofrimento é muito menos dolorido a longo prazo e produz melhores efeitos que o outro, da ciência enrijecida e seu feitiço de esquecimento. Fazendo ciência enrijecida, tentamos desesperadamente nos sacrificar para produzir um texto parecido com o dos nossos colonizadores, sem nunca conseguir produzir nada além de uma ciência local, exótica, primitiva, feminina, intuitiva, artística ou qualquer outro rótulo que aos olhos deles nos diminui.

\section{Referências}

ADORNO, Theodor W. O ensaio como forma. In: . Notas de literatura I. São Paulo: Duas Cidades; Ed. 34, 2003.

ADORNO, Theodor W. Posição do narrador no romance contemporâneo. In: Notas de literatura I. São Paulo: Duas Cidades; Ed. 34, 2003 b.

ADORNO, Theodor W. Teoria estética. Lisboa: Edições 70, 2006.

ADORNO, Theodor W. Dialética negativa. Rio de Janeiro: Jorge Zahar, 2009.

ADORNO, Theodor W.; HORKHEIMER, Max. Dialética do esclarecimento. Rio de 
Janeiro: Jorge Zahar, 1985.

BELL HOOKS. Britannica, s.d. Disponível em: https://www.britannica.com/biography/bell-hooks. Acesso em: 1 jun. 2021;

BENJAMIN, Walter. O narrador. Considerações sobre a obra de Nikolai Leskov. In: BENJAMIN, Walter. Magia e técnica, arte e política: Ensaios sobre literatura e história da cultura. São Paulo: Brasiliense, 1987. (Obras escolhidas, v. 1)

COLliNS, Patricia Hill. Pensamento feminista negro: conhecimento, consciência e a política do empoderamento. São Paulo: Boitempo, 2019.

DAVIS, Angela. Mulheres, raça e classe. São Paulo: Boitempo, 2016.

FOUCAULT, Michel. História da sexualidade, v. 1: a vontade de saber. Rio de Janeiro: Graal, 1988.

GONZALEZ, Lélia. Racismo e sexismo na cultura brasileira. Revista Ciências Sociais Hoje, Anpocs, pp. 223-244, 1984.

HARAWAY, Donna. Saberes localizados: a questão da ciência para o feminismo e o privilégio da perspectiva parcial. Cadernos Pagu, n. 5, pp. 7-41, 1995.

HOOKS, bell. Ain't I a woman: black women and feminism. London: Pluto, 1990.

HOOKS, bell. Black looks: race and representation. Boston: South End, 1992.

HOOKS, bell. Ensinando a transgredir: a educação como prática de liberdade. São Paulo: WMF Martins Fontes, 2013.

KUHN, Thomas S. A estrutura das revoluções científicas. São Paulo: Perspectiva, 1998.

LORDE, Audre. Sister outsider. Berkeley: Crossing, 2007.

NASCIMENTO, Rafael Baioni do. Solidão e formação, formação da solidão: reflexões teóricas sobre a possibilidade desprezada pela psicologia. Tese (doutorado) - Instituto de Psicologia. Universidade de São Paulo, 2014.

NASCIMENTO, Rafael Baioni do. Arte e formação: a dialética da emancipação cultural a partir de Theodor W. Adorno. Curitiba: Appris, 2021.

PIAGET, Jean. Seis estudos de psicologia. RJ: Forense Universitária, 1999. 